\title{
Contemporary Perspectives in Orthodontic Retention
}

\author{
Udhayan Asokan ${ }^{1}$, Arya J Varma ${ }^{2}$, Lidhiya Alexander ${ }^{3}$, Aniruddh V Yashwant ${ }^{4}$
}

\begin{abstract}
Retention and relapse form one of the most important components of successful orthodontic treatment. Orthodontic relapse has remained one of the persistent problems in long-term success of comprehensive orthodontic treatment. Clinical research in contemporary orthodontic scenario has determined the changes taking place several years after orthodontic treatment and its influencing factors. Factors, including growth, periodontium, age, third molars, tooth dimensions, etc., have been held responsible for posttreatment relapse. Many treatment procedures have been devised to ensure stability and prevent or at least avoid posttreatment changes so as to reduce relapse. A proper understanding of the changes and various factors affecting retention and relapse process is important. Newer orthodontic treatment modalities, though might provide an ideal end treatment result, will fail to produce a significant impact for the patient if orthodontic retention and relapse is not considered. Keywords: Orthodontic retention, Relapse, Retainers.

Journal of Scientific Dentistry (2021): 10.5005/jp-journals-10083-1010
\end{abstract}

\section{INTRODUCTION}

Relapse has been one of the most disturbing processes for orthodontists for decades. The important goal of an ideal orthodontic treatment is to create a best balance in occlusal relationship, facial and dental esthetics, stabilization of outcome, and long-term preservation and restoration of dentition. ${ }^{1}$ Retention in orthodontics is practiced by a passive appliance after proper orthodontic treatment. The working definition of retention according to Joondeph and Riedel $\mathrm{l}^{1,2}$ is "the holding of teeth in optimal aesthetic and functional positions." Retention is thus the action or fact of holding, retaining, or keeping the teeth in a fixed place or position, i.e., the condition of being retained. It is cardinal to corroborate that the retention protocol is in physiological harmony with the masticatory system function. The goal of physiological stability seems to be the practical outcome of successful treatment vs a rigid set of parameters that do not ensure long-term stability. Retention is of vital importance for most postorthodontic treatment protocol regarding three key reasons ${ }^{3}$ such as (1) the gingival and periodontal structures are overblown by orthodontic tooth movement and they require time for reorganizing when the appliances are detached from the oral cavity; (2) the teeth may be in an unstable position post treatment, thus the soft tissue constantly urge to a relapse tendency; (3) growth-related changes posttreatment also change the orthodontic treatment results. ${ }^{4}$

\section{Definition}

Retention and relapse were defined by various authors at different times and as "loss of any correction achieved by orthodontic treatment" by Moyers, "the holding of teeth in ideal esthetic and functional position" by Williams ${ }^{2}$ and in simple term as "return of the corrected malocclusion towards the original condition."

\section{History}

In the earlier years, most of the clinicians disagreed the fact of need for retention and Hellman ${ }^{6}$ in 1945 was the one who emphasized the need for retention. Different schools of thought have been developed, and present-day concepts involve these thoughts in them.

\begin{abstract}
${ }^{1-4}$ Department of Orthodontics and Dentofacial Orthopedics, Indira Gandhi Institute of Dental Sciences, Sri Balaji Vidyapeeth,
\end{abstract} Puducherry, India

Corresponding Author: Udhayan Asokan, Department of Orthodontics and Dentofacial Orthopedics, Indira Gandhi Institute of Dental Sciences, Sri Balaji Vidyapeeth, Puducherry, India, Phone: +91 9865224533, e-mail: udhayan005@gmail.com

How to cite this article: Asokan U, Varma AJ, Alexander L, Yashwant AV. Contemporary Perspectives in Orthodontic Retention. J Sci Den 2021;11(2):72-75.

Source of support: Nil

Conflict of interest: None

\section{Occlusion School}

Kingsley ${ }^{7}$ in 1880 stated, "Occlusion of the teeth is the most viable factor which determines the stability in a new position."

\section{Apical Base School}

In the middle of 1920s, a second school of thought by Lundström ${ }^{8}$ suggested that the apical base school being the vital factor in the treatment of malocclusion and maintenance. McCauley ${ }^{9}$ stated that inter canine width and inter molar width must be maintained in same positions to minimize retention difficulties. Strang and Thompson ${ }^{10}$ enhanced their views for this theory.

\section{Mandibular Incisor School}

Grieve $^{11}$ and Tweed ${ }^{12}$ enunciated that the mandibular incisors should be positioned upright and over the basal bone.

\section{Musculature School}

The need to develop proper functional muscle balance was taken into account by Rogers. ${ }^{13}$ This hypothesis was corroborated by others. Orthodontists have come to understand that retention is not distinct from orthodontic therapy but is part of the therapy itself and must be included in the preparation of treatment. Hellman ${ }^{5}$ described it aptly that in orthodontia, retention is not a separate 
problem, but it is a continuation of what we do during treatment. It is not a definite treatment stage requiring a new technique; hence, there is no need for it to be carried out by a separate machinery. Retention is but a letting go of what we did during therapy. The improvements we make in our machinery are to ease the pressures and stresses and wean the tissues away from the effects of all our tinkering so that the appliance can decrease any change that is made. This can be achieved by adjusting either the form of the system or the amount of time it takes to wear it. Until retention is applied, a total outcome must be obtained.

\section{Raleigh Williams Keys to Eliminate Lower ReLAPSE}

- Incisal edge of lower incisors should be in an anteroposterior line or $1 \mathrm{~mm}$ in front of it.

- All four mandibular incisors must be in the same labiolingual plane.

- Lower incisors apices should be spread distally to the crowns.

- Lower incisors should be slenderized as needed after treatment.

- Apex of lower cuspids should be distal to the crown.

- Apex of lower cuspid should be slightly buccal to the crown apex.

In orthodontic treatment, stability has become a primary target, and without it, ideal function or ideal esthetics or both can be lost. During recovery, retention depends on what is done. Within the limits of normal muscle balance and with particular attention to the apical base or bases available and the relationships of these bases to one, care must be taken to create a proper occlusion.

\section{Current Trends in Retention Conventional Retainers \\ Removable Retainers}

These retainers are passively fitted and are worn by the patients for a period of least 6-12 months after treatment completion therefore the remodeling of surrounding structures of the teeth to take place. These removable retainers (Figs 1 to 3 ) act as a retention device for intra-arch stabilization and in patients with altered growth conditions. ${ }^{3}$

\section{Fixed Retainers}

A fixed retainer is usually a passive bonded wire to the lingual side of the tooth usually in mandibular anterior region. Mounted retainers are used in cases of questionable stability and permanent retention

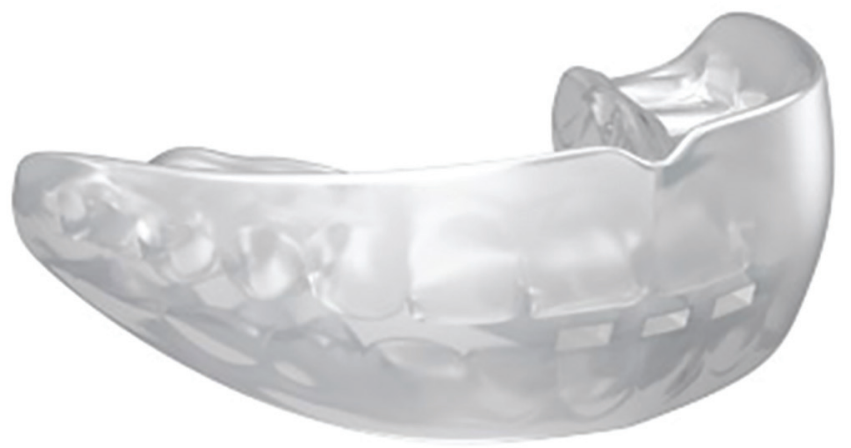

Fig. 1: Tooth positioner

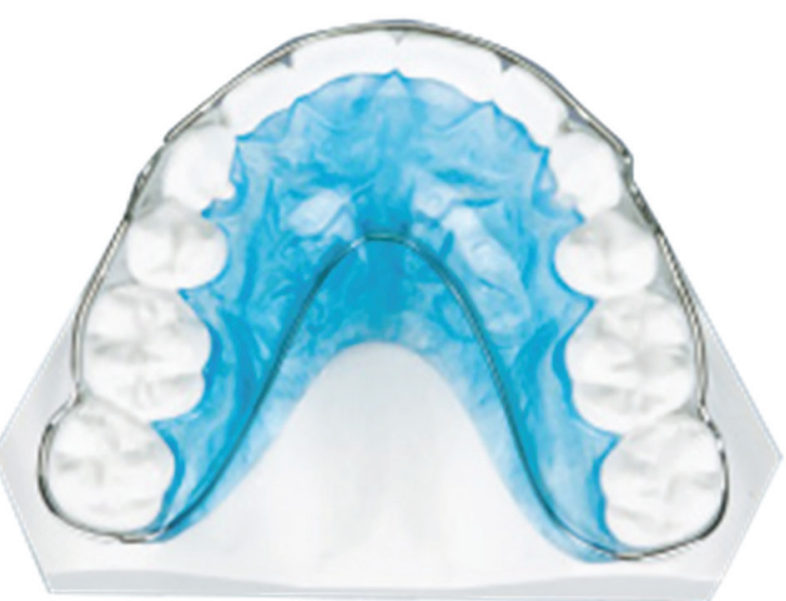

Fig. 2: Begg wrap around retainer

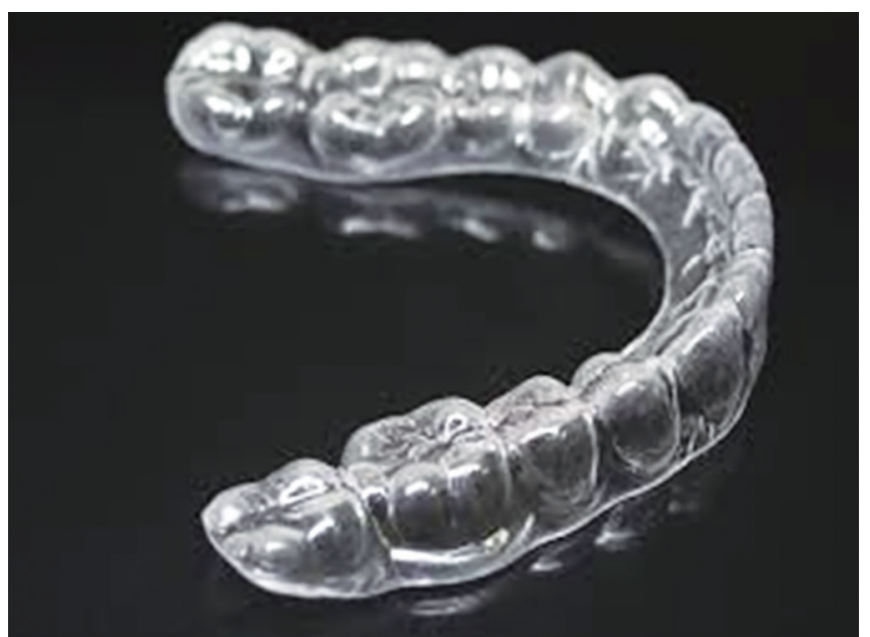

Fig. 3: ESSIX (thermoformed) retainer

required cases (Figs 4 and 5). ${ }^{3}$ There are various types of mounted retainers and are as follows: banded canine to canine retainer, bonded lingual retainers, band and spur retainer.

\section{Newer Retainers}

\section{Memotain}

The name Memotain is obtained by the mix of "memory" and "retainer" due to the unique usage of $\mathrm{Ni}$-Ti wire for the lingual aspect (Fig. 6). It is a CAD/CAM fabricated lingual retainer made of $0.014 \times 0.014$ in rectangular nickel-titanium wire which adapts closely to the tooth anatomy and was introduced by Pascal Schumacher in 2012. This tight interproximal adaptation of the retainer is beneficial in common break-point areas, such as the embrasure between the lateral incisor and the canine or the step between the canine and the premolar, and it is digitally positioned to prevent hindrance with the mandibular teeth. ${ }^{14}$

\section{Adjunctive Techniques and Methods to Minimize Relapse \\ Circumferential Supracrestal Fiberotomy}

Circumferential supracrestal fiberotomy (CSF) is a surgical periodontal procedure that is performed to detach the free gingiva and 


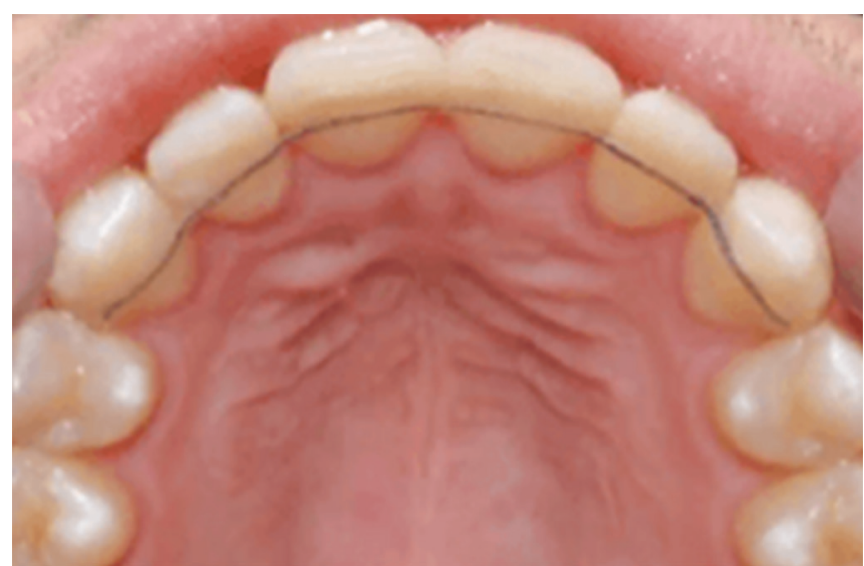

Fig. 4: Fixed lingual retainer

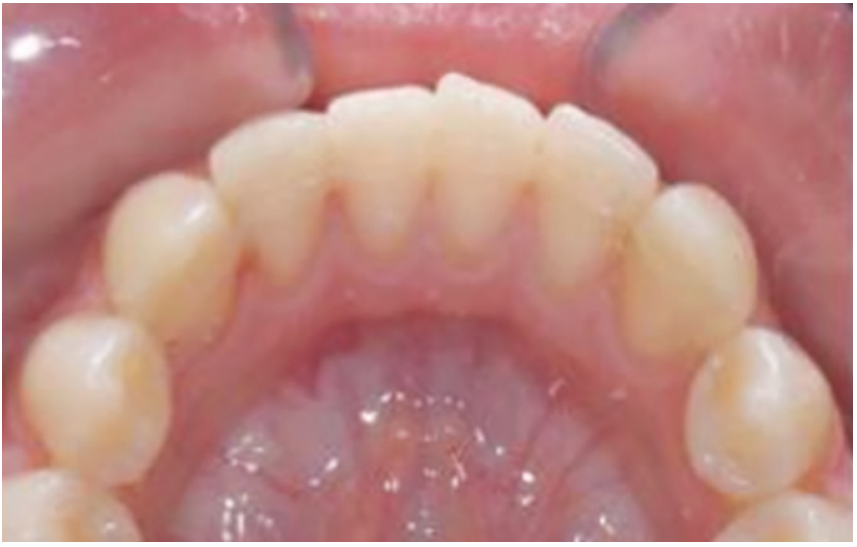

Fig. 5: Resin fiberglass bonded retainer

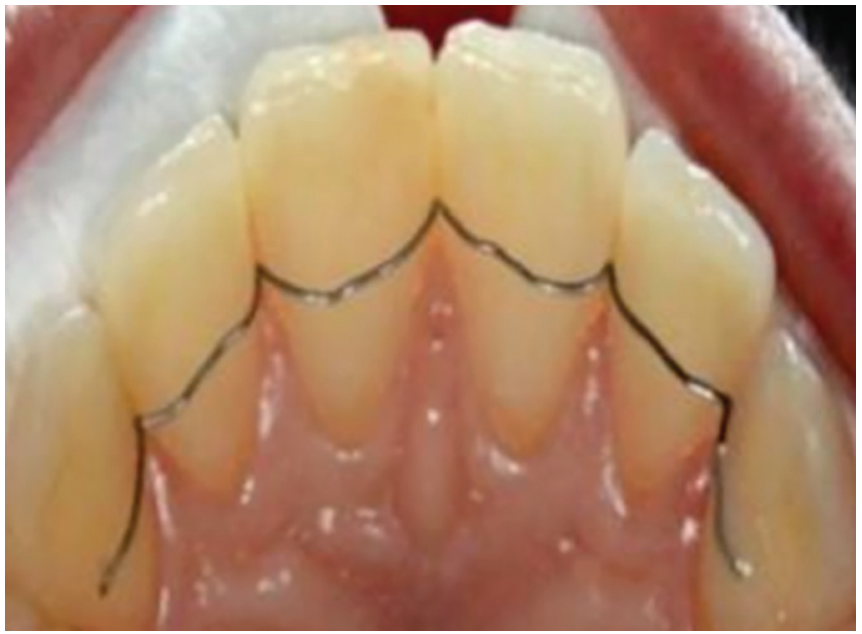

Fig. 6: Memotain appliance

trans-septal fibers around orthodontically aligned or derotated teeth. This detachment reduces tension taking place from these fibers that pull teeth into their original state, hence preventing relapse. ${ }^{15}$

\section{Pharmacological Aids}

In retention phase, inhibition of relapse has been carried out by administering drugs to control the relapse condition to an extent.
By administering raloxifene, it decreases RANKL expression, administering aspirin through CD4+ T lymphocytes inhibits relapse, and administration of systemically and locally available drugs such as bisphosphonates, osteoprotegerin, simvastatin, relaxin, etc., also reduce and prevent the amount of relapse postorthodontic treatment and are highly recommended drugs of choice on retention these days. ${ }^{16-21}$

\section{Discussion}

Kravitz et al. conferred that Memotain has potential advantages to the traditional multistranded stainless steel wire, including precise adaptation, devoid of interferences, resistance to corrosion, and even minor tooth movement as an active lingual retainer. This retainer is a new clinical appliance, and further more research is needed in the coming years. ${ }^{22}$ Wegrodzka et al. in their recent randomized control trial involving 133 patients of age between 15 and 50 years compared the survival rates and periodontal health condition in patients with three-stranded round twisted (RT) vs eight-stranded rectangular braided (RB) fixed retainers which were bonded to all six anterior teeth in the mandibular arch. The authors through their research study culminated that the first time failing of the fixed retainer was about $52.3 \%$ (56.1\% in the RT group and $48.5 \%$ in the RB group), which is of high deterioration rate in the retention phase. There was no difference in terms of survival or periodontal health between the examined retainers. ${ }^{23}$ Various authors have reported in their studies about the comparison of removable retainers vs fixed retainers, and majority of them concluded that the effectiveness of permanent retainers is way higher than that of removable retainers though they are also relatively effective. Orthodontist nowadays recommend lifelong retention with bonded retainers are increasing over the globe with the phrase "Braces for Life." 24

\section{CONCLUSION}

Orthodontic treatment goal is to achieve good esthetics and occlusal function with stability over the years, and retention phase is important to achieve posttreatment stability, and it is mandatory to plan the requirements of retention at the time of diagnosis and treatment planning. Therefore, retention of the treated malocclusion is as important as the diagnosis and treatment plan. ${ }^{25}$ However, as trained orthodontists, it is incumbent on us to take a more proactive approach in dealing with the actions associated with relapse.

\section{References}

1. Joondeph DR, Riedel RA. Retention. In: Graber TM, Swain BF, editors. Orthodontics. Principles and techniques; 1985. p. 857-898.

2. Williams R. Eliminating lower retention. J Clin Orthod 1985;19(5): 342-349. PMID: 3859488.

3. Malandkar A, Toshniwal NG, Mote N, Das S, Singh N. An overview of current trends in retention. Int J Appl Dent Sci 2019;5(3):2394-7497. ISSN ONLINE: 2394-7497.

4. Reidel RA. A review of retention problems, Angle Orthod 1960;30(4). DOI: 10.1043/0003-3219(1960)030<0179:AROTRP>2.0.CO;2.

5. Moyers RE. Handbook of orthodontics for the student and general practitioner. 3rd ed. Chicago, London.

6. Hellman M. Fundamental principles and expedient compromises in orthodontic procedures. Am J Orthod Oral Surg 1944;30(8):429-436. PMID: 21024941. 
7. Kingsley NW. A treatise on oral deformities as a branch of mechanical surgery. D. Appleton; 1880.

8. Lundstrom A. Malocclusions of the teeth regarded as a problem in connection with apical base. Int J Orthod Oral Surg 1925;11(12): 591, 125. DOI:10.1016/S0099-6963(25)90386-9.

9. McCauley DR. The cuspid and its function in retention. Am J Orthod Oral Surg 1944;30(4):196-205. DOI: 10.1016/S0096-6347(44)90227-9.

10. Strang RHW, Thompson WM. Textbook of orthodontia. 5th ed. Lea \&Febiger: Philadelphia; 1958.

11. Grieve GW. The stability of the treated denture. Am J Orthod Oral Surg 1944;30(4):171-195. DOI: 10.1016/S0096-6347(44)90226-7.

12. Tweed $\mathrm{CH}$. Indications for the extraction of teeth in orthodontic procedure. Am J Orthod Oral Surg 1944;30(8):405-428. PMID: 21024940.

13. Rogers AP. Making facial muscles our allies in treatment and retention. Dental Cosmos 1922;64(7):711-730. Available from: https://quod.lib. umich.edu/d/dencos?page=home.

14. Rami Reddy MS, Suma S, Chandrasekhar BR, Chaukse A. Retention appliances - a review. Int J Dent Clin 2010;2(3):31-36. DOI:10.13005/ $\mathrm{bpj} / 749$.

15. Edwards JG. A long-term prospective evaluation of the circumferential supracrestal fiberotomy in alleviating orthodontic relapse. Am J Orthod Dentofacial Orthop 1988;93(5):380-387. DOI: 10.1016/0889-5406(88)90096-0.

16. Azami N, Chen PJ, Mehta S, Kalajzic Z, Dutra EH, Nanda R, et al. Raloxifene administration enhances retention in an orthodontic relapse model. Eur J Orthod 2020;42(4):371-377. DOI: 10.1093/ejo/cjaa008.

17. Liu Y, Zhang T, Zhang C, Jin SS, Yang RL, Wang XD, et al. Aspirin blocks orthodontic relapse via inhibition of CD4+ Tlymphocytes. J Dent Res 2017;96(5):586-594. DOI: 10.1177/0022034516685527.
18. Kim TW, Yoshida Y, Yokoya K, Sasaki T. An ultrastructural study of the effects of bisphosphonate administration on osteoclastic bone resorption during relapse of experimentally moved rat molars. Am J Orthod Dentofacial Orthop 1999;115(6):645-653. DOI: 10.1016/ s0889-5406(99)70290-8.

19. Zhao N, Lin J, Kanzaki H, Ni J. Local osteoprotegerin gene transfer inhibits relapse of orthodontic tooth movement. Am J Orthod Dentofacial Orthop 2012;141(1):30-40. DOI: 10.1016/ j.ajodo.2011.06.035.

20. Han G, Chen Y, Hou J, Liu C, Chen C, Zhuang J, et al. Effects of simvastatin on relapse and remodeling of periodontal tissues after tooth movement in rats. Am J Orthod Dentofacial Orthop 2010;138(5):550. DOI: 10.1016/j.ajodo.2010.04.026.

21. Hirate $Y$, Yamaguchi M, Kasai K. Effects of relaxin on relapse and periodontal tissue remodeling after experimental tooth movement in rats. Connect Tissue Res 2012;53(3):207-219. DOI: 10.3109/03008207.2011.628060.

22. Kravitz ND, Grauer D, Schumacher P, Jo YM. Memotain: a CAD/CAM nickel-titanium lingual retainer. Am J Orthod Dentofacial Orthop 2017;151(4):812-815. DOI: 10.1016/j.ajodo.2016.11.021.

23. Węgrodzka E, Kornatowska K, Pandis N, Fudalej PS. A comparative assessment of failures and periodontal health between 2 mandibular lingual retainers in orthodontic patients. A 2-year follow-up, single practice-based randomized trial. Am J Orthod Dentofacial Orthop 2021;160(4):494-502. DOI: 10.1016/j.ajodo.2021.02.015.

24. Littlewood SJ, Kandasamy S, Huang G. Retention and relapse in clinical practice. Aust Dent J 2017;62:51. DOI: 10.1111/adj.12475.

25. Loli D. Retention after orthodontic treatments: a systematic review. WebmedCentral Orthodontics 2017;8(11):WMC005406. 